\title{
Association between calcifying nanoparticles and placental calcification
}

This article was published in the following Dove Press journal:

International Journal of Nanomedicine

23 March 2012

Number of times this article has been viewed

\section{Yanan Guo' \\ Dechun Zhang' \\ $\mathrm{He} \mathrm{Lu}^{\prime}$ \\ Shuang Luo ${ }^{2}$ \\ Xuecheng Shen ${ }^{3}$}

'Molecular Medicine and Tumor Research Center, Chongqing Medical University, Yuzhong District,

${ }^{2}$ Department of Obstetrics and Gynecology, First Affiliated Hospital of Chongqing Medical University, ${ }^{3}$ Urological Research Institute of PLA, Southwest Hospital, Third Military Medical University, Chongqing, People's Republic of China
Correspondence: Dechun Zhang Molecular Medicine and Tumor Research Center, Chongqing Medical University, I Medical College Road,

Yuzhong District, Chongqing, 4000 16, People's Republic of China

$\mathrm{Tel}+8602368486133$

Fax +8602368486133

Email zhangdechun46@I63.com
Background: The purpose of this study was to examine the possible contribution of calcifying nanoparticles to the pathogenesis of placental calcification.

Methods: Calcified placental tissues and distal tissue samples were collected from 36 confirmed placental calcification cases. In addition, 20 normal placental tissue samples were obtained as a control group. All the tissue samples were cultured using special nanobacterial culture methods. The cultured calcifying nanoparticles were examined by transmission electron microscopy (TEM), and their growth was monitored by optical density (OD) at a wavelength of $650 \mathrm{~nm}$. 16S rRNA gene expression of the cultured calcifying nanoparticles was also isolated and sequenced.

Results: Novel calcifying nanoparticles wrapped with electron-dense shells between $50 \mathrm{~nm}$ to $500 \mathrm{~nm}$ in diameter were observed in the extracellular matrix of calcified placental tissues. They were detected in placental villi and hydroxyapatite crystals, and contained "nucleic acidlike materials". After isolation and four weeks of culture, 28 of 36 calcified placental tissue samples showed white granular precipitates attached to the bottom of the culture tubes. $\mathrm{OD}_{650}$ measurements indicated that the precipitates from the calcified placental tissues were able to grow in culture, whereas no such precipitates from the control tissues were observed. The $16 \mathrm{~S}$ rRNA genes were isolated from the cultured calcifying nanoparticles and calcified placental tissues, and their gene sequencing results implied that calcifying nanoparticles were novel nanobacteria (GenBank JF823648).

Conclusion: Our results suggest that these novel calcifying nanoparticles may play a role in placental calcification

Keywords: calcifying nanoparticles, nanobacteria, placental calcification, 16S rRNA gene

\section{Introduction}

Placental calcification is a common pathological change of the placenta during pregnancy. In general, more than $50 \%$ of placentas have some degree of calcification and $18 \%$ of placentas show severe grade $3+$ calcification after about 33 weeks of pregnancy. ${ }^{1}$ Early preterm placental calcification is associated with a higher incidence of detrimental outcomes, thus may serve as a diagnostic marker. ${ }^{2}$ Other studies have indicated that rickets in offspring are associated with placental calcification, ${ }^{3}$ and placental dysfunction during early gestation may play an important role in the development of hypospadias. ${ }^{4}$ In addition, calcium deposition is harmful for placental function and may cause severe complications in pregnancy, such as fetal distress, fetal growth restriction, fetal anomaly, and apnea neonatorum. Previous studies of calcified placentas are limited, and the 
etiology of placental calcification remains undefined. Most clinicians believe that placental calcification results from hereditary and environmental factors, such as radiation, low frequency noises, or reactions to medication. Some studies indicate that smoking is not a factor exclusively responsible for forming calcium deposits in the placenta, and the consumption of vitamin supplements probably also involves calcification of placental tissues. ${ }^{5}$ Recently, interleukins 1 and 6, which are immunity-related cytokines, were identified in placental fluid from placental calcification cases ${ }^{6}$ and Mycoplasma and other organisms were isolated from the placenta after cesarean section. ${ }^{7}$ The results indicate that bacterial infections may play an important role in placental calcification.

Kajander and Ciftcioglu and Kajander et al proposed that calcifying nanoparticles may be responsible for some calcification diseases, which spurred a subdiscipline in nanoscale paleontology. ${ }^{8,9}$ These entities were described earlier in geological samples, including fossils, ${ }^{10}$ hot spring sediments, ${ }^{11,12}$ and a martian meteorite, ${ }^{13}$ indicating that nanobacteria may have existed throughout earth's history. These bacteria, with diameters from $50 \mathrm{~nm}$ to $500 \mathrm{~nm}$, are sterile and filterable. They contain a sodium carbonate salt shell, and are capable of self-mineralization in physiological conditions. These nanobacteria are implicated in many human diseases, including kidney and gallbladder stones, testicular microliths, chronic prostatitis, rheumatoid arthritis, dental pulp stones, salivary gland stones, ovarian cancer, and atherosclerosis. ${ }^{14-30}$ Calcifying nanoparticles were found to be opportunistic pathogens in 5\% of Finns and $8 \%$ of Chinese individuals ${ }^{31}$ on blood testing. In addition, calcifying nanoparticle infections have also been observed in placental calcification and psammoma bodies. ${ }^{32,33}$ Nanobacteria grow faster in elevated phosphates than in normal culture medium, so may be implicated in placental calcification because elevated phosphates generally stimulate smooth muscle cell mineralization. ${ }^{34}$ Whether these self-mineralizing nanobacteria are bacterial or inorganic substances with the capacity for extensive crystallization is still in debate. ${ }^{35-37}$ Many of the 16S rRNA gene sequences of nanobacteria in the GenBank are $\alpha-2$ subgroups of Proteobacteria, such as Brucella and Bartonella species. Here we examine the morphology of calcifying nanoparticles under transmission electron microscopy (TEM), and characterize their biological growth properties with optical density (OD). In addition, 16S rRNA gene expression of calcifying nanoparticles was isolated, sequenced, and deposited into GenBank (GenBank JF823648).

\section{Materials and methods}

\section{Clinical sample collection}

All enrolled patients agreed to sign written consent forms and the study was approved by our institutional review board. Thirty-six pregnant women, aged 22-40 (median 33) years were diagnosed with placental calcification disease by ultrasound, and were scheduled to deliver by cesarean section. These pregnant women were enrolled in this study at the First Affiliated Hospital of Chongqing Medical University. None of the women had any other infectious diseases, such as Treponema pallidum, human immunodeficiency virus, or hepatitis $\mathrm{B}$ and $\mathrm{C}$, and all underwent routine testing of blood, urine, and feces. Three biopsies from each patient's placenta (about $50 \mathrm{~mm}^{3}$ of each sample) were collected immediately after removal of the placenta. They were kept in an ice-box for either immediate laboratory research or storage at $-80^{\circ} \mathrm{C}$. The control group biopsies were collected from the placental tissues of healthy pregnant women.

\section{TEM of calcifying nanoparticles in calcified placental tissues}

Fresh specimens from calcified placental tissues and normal tissue samples were cut into small pieces (about $1 \mathrm{~mm}^{3}$ ), fixed in $2.5 \%$ glutaraldehyde, post-fixed in $1 \%$ osmic acid, and dehydrated by a graded series of cold ethanol solutions before embedding in epoxy and being sliced into ultrathin sections. The thin sections were viewed under TEM to image the mineral microdeposits. ${ }^{38}$

\section{Isolation and cultivation of calcifying nanoparticles}

After removal of blood and villous tissue, the calcified placental tissue samples (around $100 \mathrm{mg}$ ) were ground, decalcified in $1 \mathrm{~mol} / \mathrm{L} \mathrm{HCl}$ for 30 minutes, and neutralized with $1 \mathrm{~mol} / \mathrm{L}$ Tris, followed by centrifugation at $14,000 \mathrm{~g}$ for 40 minutes in normal saline and filtering with $0.22 \mu \mathrm{m}$ Millipore filters. The samples were then incubated in a $70^{\circ} \mathrm{C}$ water bath for 15 minutes to prevent contamination by Chlamydia and Mycoplasma. Next, $1 \mathrm{~mL}$ samples were mixed with $3 \mathrm{~mL}$ RPMI-1640 cell culture medium supplemented with $10 \%$ fetal bovine serum. The mixture was cultured in an incubator $\left(37^{\circ} \mathrm{C} ; 5 \%-10 \% \mathrm{CO}_{2} / 90 \%-95 \%\right.$ air) for 4 weeks, with medium changes every 3 days. ${ }^{8}$ Fetal bovine serum or normal saline was used as the vehicle control; and normal placental tissues which were decalcified and cultured under the same conditions were used as the negative control. All the 
procedures were performed under aseptic conditions, and freedom from contamination by Chlamydia and Mycoplasma was verified after 4 weeks of culture.

\section{Identification of cultured calcifying nanoparticles}

After about 4 weeks of culturing, the calcifying nanoparticles were harvested using a cell scraper, centrifuged at 14,000 g for 40 minutes, and washed for 5 minutes with PBS, repeated three times. The precipitates collected were then fixed in $2.5 \%$ glutaraldehyde, post-fixed in 1\% osmic acid, dehydrated in ethanol, and embedded in epoxy as described above. The calcifying nanoparticle precipitates were observed using a Hitachi-600 TEM operated at $120 \mathrm{kV}$. Next, $200 \mu \mathrm{L}$ aliquots of calcifying nanoparticles were placed in a 96-well plate in triplicate and OD was measured every three days at $650 \mathrm{~nm}$ using a microplate spectrophotometer ( $\mu$ Quant; Biotek, North Seattle, WA). The averages of the OD outcomes were recorded separately for each group.

\section{I6S rRNA gene expression of cultured calcifying nanoparticles}

The cultured calcifying nanoparticle precipitates were first decalcified with $1 \mathrm{M} \mathrm{HCl}$. Genomic DNA was then isolated from the decalcified precipitates using the Wizard ${ }^{\circledR}$ genomic DNA purification kit (Promega, Madison, WI) following the manufacturer's instructions. 16S rDNA sequences for Nanobacterium sanguineum (Genbank X98418), Microscilla species Nano 1 (Genbank AB015937), and nanobacterium species NanoD (Genbank EF585587) were obtained from the National Center for Biotechnological Information, and multialigned using Vector NTI Suite 6.0. A pair of nanobacteria group-specific polymerase chain reaction (PCR) primers was designed and synthesized (Shanghai Bioasia Biotechnology Corporation Ltd, Shanghai, China) to amplify the 16S rDNA. The primer sequences are as follows: upstream primer (NanoA), 5'-CACCCCAGTCATCGGCCA CACCGTGGCAA-3'; downstream primer (NanoB), 5'-AA CGCTGGCGGTAGGCCTAACACATGCAA-3'. The PCR reaction solutions $(50 \mu \mathrm{L})$ contained $250 \mathrm{ng}$ of genomic DNA template, 10 pmol of each primer, $2.5 \mathrm{U}$ of AmpliTaq DNA polymerase, $3 \mathrm{mM} \mathrm{MgCl}, 50 \mathrm{mM} \mathrm{KCl}, 20 \mathrm{mM}$ Tris- $\mathrm{HCl}$, and $0.5 \mathrm{mM}$ of each dNTP. Negative PCR controls were conducted without primers or templates or genomic DNA templates from normal placental tissues.

PCR reactions were performed with the GeneAmp PCR system 2400 (Perkin Elmer, Norwalk, CT). The thermal program consisted of one cycle at $94^{\circ} \mathrm{C}$ ( 4 minutes), 35 cycles of $94^{\circ} \mathrm{C}$ for 30 seconds, $56^{\circ} \mathrm{C}$ for 20 seconds, and $68^{\circ} \mathrm{C}$ for 40 seconds, and one cycle of $68^{\circ} \mathrm{C}$ for 10 minutes, then stored at $4{ }^{\circ} \mathrm{C}$. The PCR products were subjected to electrophoresis and the desired DNA bands were then purified with the PCR purification kit (Takara Biotechnology [Dalian] Co, Ltd, Dalian, China) according to the manufacturer's instructions. The purified DNA products were inserted into a pMD18-T vector (Takara Biotechnology [Dalian] Co, Ltd) and transformed into Escherichia coli DH5 $\alpha$. One microgram of purified plasmid was used for sequence analysis of the cloned 16S rRNA gene fragments.

\section{I6S rRNA expression of calcifying nanoparticles in calcified placentas}

Samples with calcium deposits and normal placental samples were excised to isolate genomic placental DNA. A pair of PCR primers was designed against the newly-found 16S rRNA gene sequences from cultured calcifying nanoparticles: upstream primer (NanoA), 5'-TAGGGTTTCTGGGATTGGC-3'; downstream primer (NanoB), 5'-ATTTGGCACGCAGTATCG-3' (GenBank JF823648). Negative PCR controls were performed without primers or genomic DNA or genomic DNA from normal placental tissues. The amplified fragment was purified, cloned, and analyzed as described elsewhere.

\section{Results \\ Isolation of calcifying nanoparticles from calcified placental tissues}

The morphology of calcifying nanoparticles under TEM in freshly-fixed calcified placental tissues was very similar to that described in other studies. ${ }^{32}$ In all the fixed calcified placental samples, the particles had an oval shape and were of different sizes, ranging from $50 \mathrm{~nm}$ to $500 \mathrm{~nm}$ in diameter. Each particle was wrapped by a thin shell with different electron densities (Figure 1A). We observed similar "nucleic acid-like materials" in the extracellular matrix of each individual particle as described by Agababov et al ${ }^{132}$ (Figure 1B). Interestingly, one calcifying nanoparticle was seen in the process of self-dividing (Figure 1C). The calcifying nanoparticles were also seen in the uterus among placental villi (Figure 1D) and free hydroxyapatite crystals (Figure 1E). There was no evidence of needle precipitates or caves in placental tissues whereby these particles form hydroxyapatite crystals. In contrast, no calcifying nanoparticles were found in normal placental tissues under TEM. 


\section{Calcifying nanoparticle culture results}

After 4 weeks of culture, the 36 calcified placental tissue samples were classified into three groups according to their adhesion and turbidity characteristics: $:^{13}$ Group 1 , complete white precipitation adhered to the bottom of glass tubes; Group 2, white precipitation adhered to the bottom of the glass test tubes with flocculent floating debris; and Group 3, no particles. Twenty-eight placental calcification samples (10 samples in Group 1 and 18 samples in Group 2) were able to grow in culture. The negative controls and reagent controls were all classified in Group 3. $\mathrm{OD}_{650}$ measurements during culture indicated that the calcifying nanoparticles grew in a similar way to that of other bacteria (Figure 2). Significant differences were observed between the experimental group and the negative group, and no Chlamydia or Mycoplasma was detected.
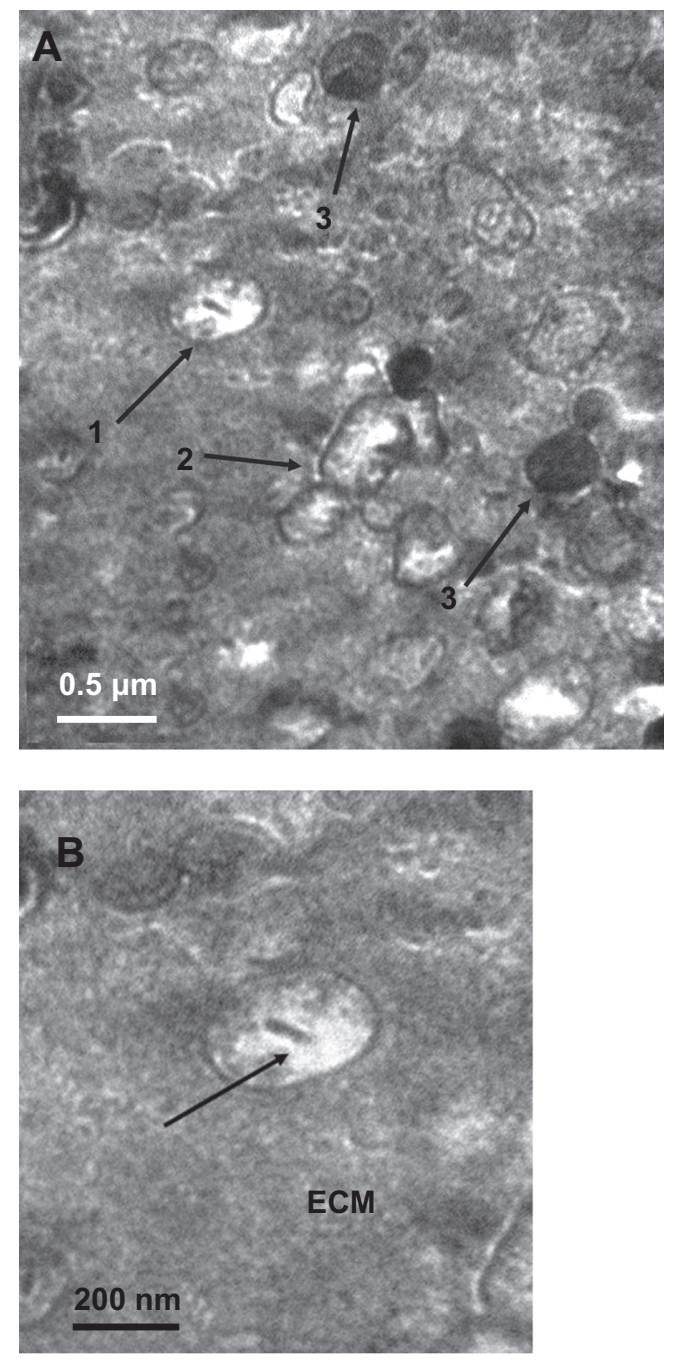

Figure I (Continued)
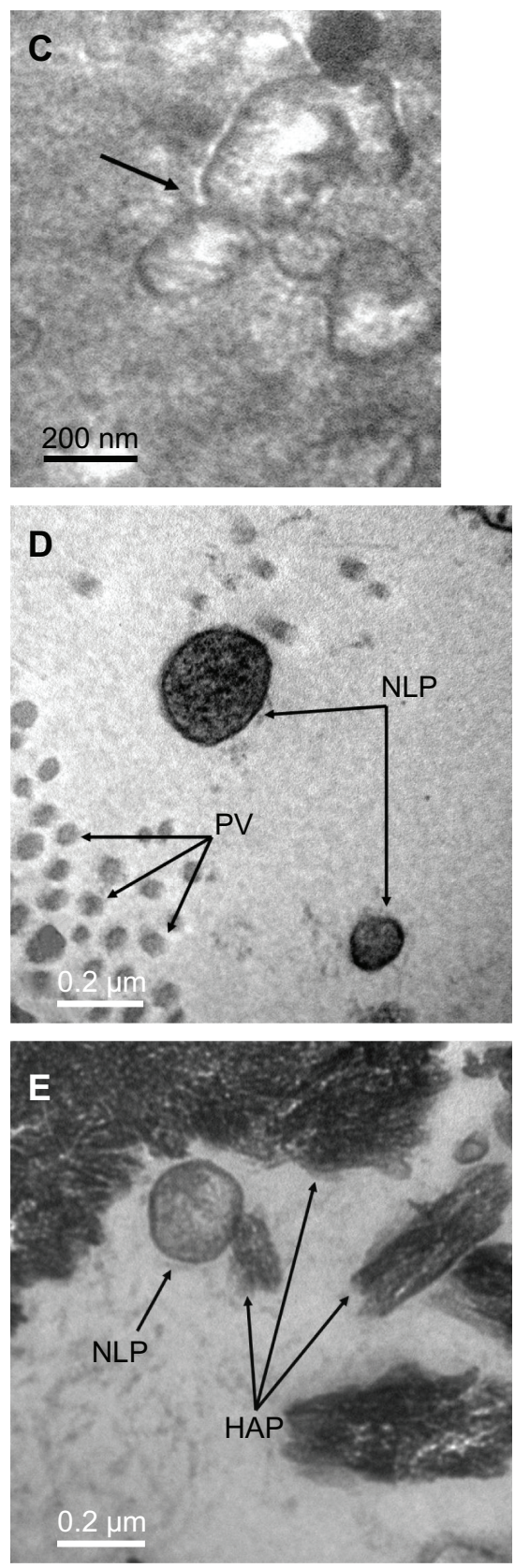

Figure I Transmission electron micrograph of calcifying nanoparticles. (A) Calcifying nanoparticles between $50 \mathrm{~nm}$ to $500 \mathrm{~nm}$ in diameter showing different electron-dense shells in calcified placental tissues. (B) Nucleic acid-like materials distributed within the individual calcifying nanoparticles in the extracellular matrix. (C) A calcifying nanoparticle self-divided into two. (D) Calcifying nanoparticles with thin shells exiting placental villus. (E) Single calcifying nanoparticles among hydroxyapatite crystals in calcified placental tissues.

Note: Bar indicates magnification of $200 \mathrm{~nm}$.

\section{Morphologic characteristics of cultured calcifying nanoparticles}

Gram staining of the calcifying nanoparticle precipitates did not work well, and only some deep-colored particles with no stains could be observed under high-power magnification using light microscopy. In contrast, TEM is a powerful tool 


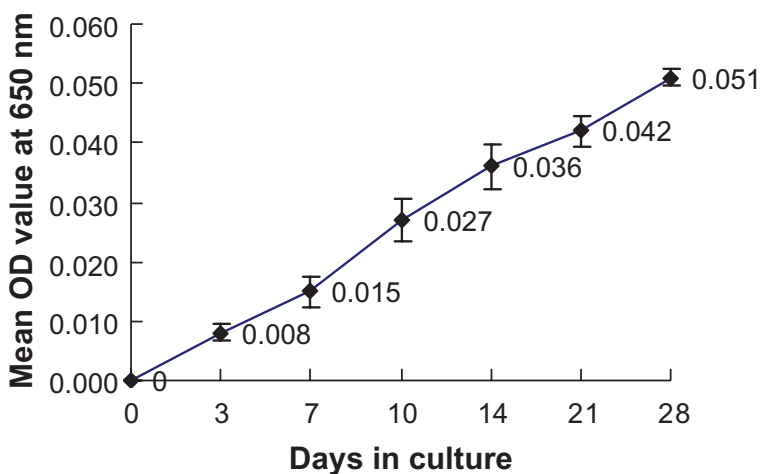

Figure 2 Growth curve of calcifying nanoparticles cultured in vitro under cell culture conditions.

Note: Mean $O D_{650}$ values were recorded up to 4 weeks.

Abbreviation: $O D$, optical density.

to study calcifying nanoparticles. After four weeks of culture, oval-shaped particles with diameters of 200-400 nm were observed using TEM. These cultured particles were similar in size and shape to the calcifying nanoparticles detected in tissues, and each particle was either wrapped by a high electron-dense outer shell (Figure 3A) or without shells (Figure 3B). The needle-like features on the outer surfaces of the calcifying nanoparticles which were described in previous reports were not observed here. ${ }^{32}$

\section{I6S rRNA expression by calcifying nanoparticles}

The predicted target 16S rRNA gene sequence of cultured calcifying nanoparticles is about 1500 base pairs in length (Figure 4). Our PCR-amplified DNA is 1470 base pairs in length, as indicated by DNA sequencing, and shares $83 \%$ similarity to the known 16S rRNA gene for nanobacteria (GenBank X98419). The novel 16S rRNA gene in placental calcification tissues (GenBank JF823648) was identified in 11 calcified placenta samples (31\%, Figure 4$)$, while no target $16 \mathrm{~S}$ rRNA gene was detected in the controls (Figure 5). The sequence of the 16S rRNA gene (nanobacterial PCR) for placenta calcification is different to that of other nanobacteria in human stone disease, human blood, or fetal bovine serum. This novel 16S rRNA gene sequence was submitted to the NCBI GenBank database (GenBank JF823648).

\section{Discussion}

Nanobacteria are thought to promote the development of stone disease and calcified plaques in adults. ${ }^{39-41}$ Putative nanobacteria have been described using both transmission and scanning electron microscopy, but the immunochemical specificity of these putative nanobacteria has not been established, and DNA staining (Hoechst 33258)
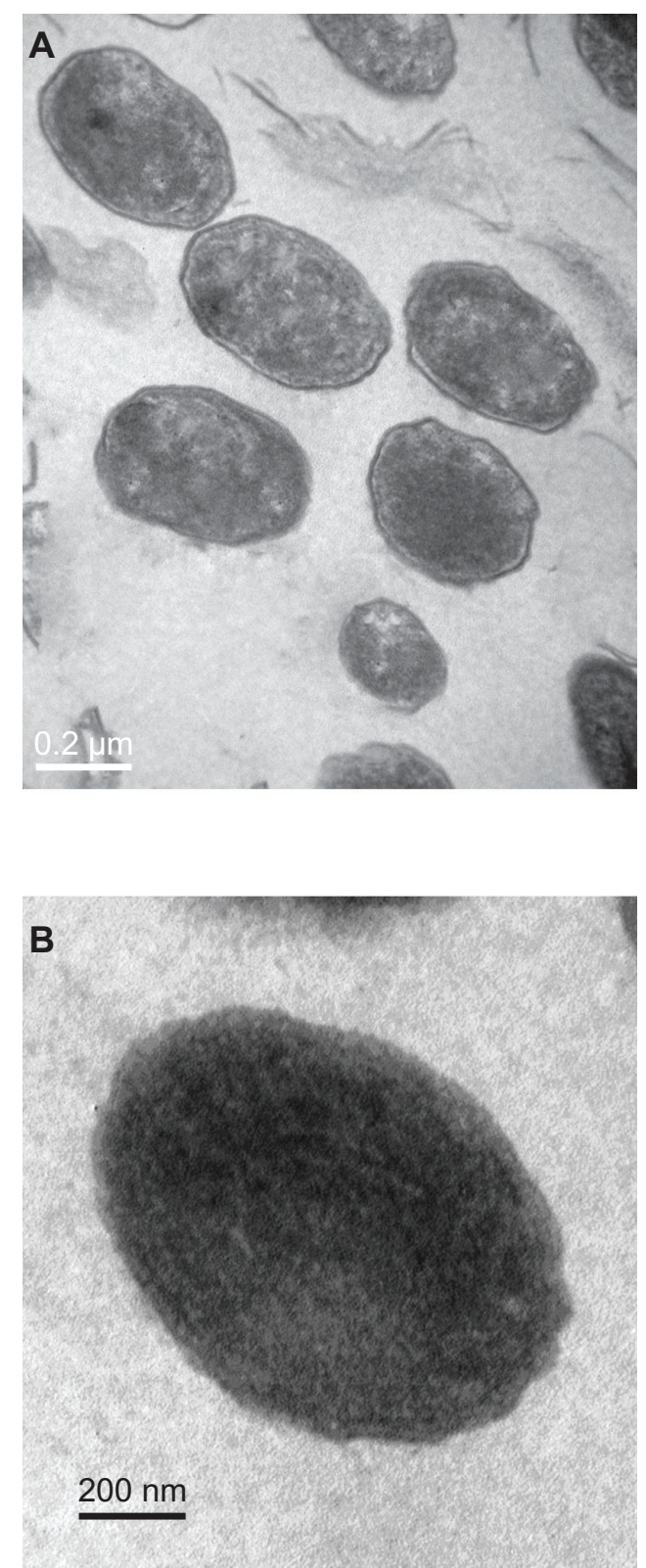

Figure 3 Transmission electron micrograph of calcifying nanoparticles cultured in vitro for four weeks. (A) Calcifying nanoparticles appear as oval-shaped particles with highly electron-dense shells. (B) Calcifying nanoparticles without shells. Note: Bar indicates magnification of $200 \mathrm{~nm}$.

at the concentration used did not stain the nanobacteria. ${ }^{42,43}$ Furthermore, the 16S rRNA gene sequences reported for nanobacteria are thought to come from contaminating bacteria. ${ }^{44}$ Thus, many scientists consider nanobacteria as nonliving organic or inorganic substances with the capacity to aggregate and grow. Here, we showed that calcifying nanoparticles adhered to the bottom of glass culture tubes and displayed growth curves similar to other bacteria. "Nucleic acid-like materials" in the extracellular matrix of individual particles could be observed in placental 


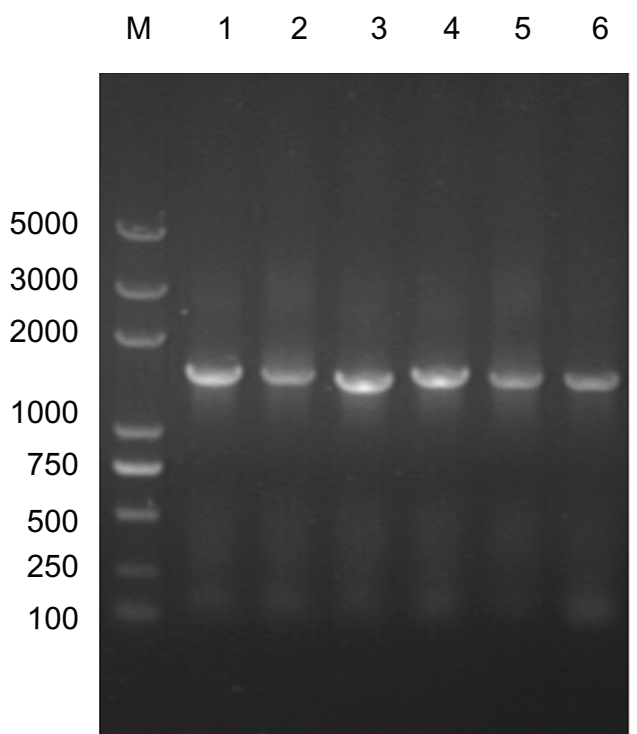

Figure 4 Analysis of target I6S rRNA gene sequences from different cultured calcifying nanoparticle samples. Lane M, DNA marker (Trans2K plus DNA marker); lane $1-6$, genes from different calcifying nanoparticle samples cultured under the same conditions.

calcification tissues under TEM. Consistent with previous studies, ${ }^{45}$ we also observed one particle in the process of self-dividing. In addition, we successfully detected the $16 \mathrm{~S}$ rRNA gene in calcifying nanoparticles isolated from placental calcification tissue, and the DNA sequencing results indicated that the calcifying nanoparticles are novel nanobacteria. Taken together, our data support the notion that calcifying nanoparticles are living materials, rather than protein or hydroxyapatite.

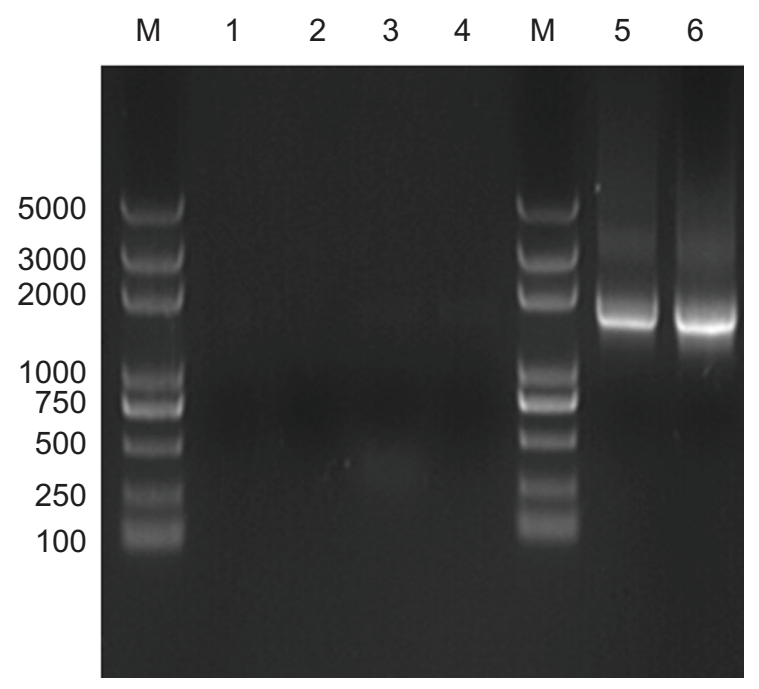

Figure 5 Analysis of target I6S rRNA gene sequences from different samples of calcified placental tissues and normal placental tissues. Lane M, DNA marker (Trans2K plus DNA marker); lane I, negative polymerase chain reaction control without primers; lane 2, negative polymerase chain reaction control without templates; lane 3-4, genes from normal placental tissues samples; lane 5-6, genes from different calcium samples.
We initially attempted to isolate bacteria from the calcified tissue using normal culture methods and failed. Eventually, white precipitates (calcifying nanoparticles) were obtained using the culture methods described for nanobacteria. The 16S rRNA genes amplified from the cultured calcifying nanoparticles in placental calcification tissues share 83\% gene similarity with nanobacteria (GenBank X98419). They could not reach up to $98 \%$ gene similarity with the nanobacteria (GenBank X98419), as reported previously. ${ }^{15}$ We have speculated that the calcifying nanoparticles in placental calcification are a novel type of nanoscale bacteria distinct from the nanobacteria isolated from kidney stones and human blood, as reported elsewhere. ${ }^{46}$ We assumed that different nanobacteria may induce calcification by receptors in different human tissues, like nanobacteria receptormediated tumor tissue calcification.

It is unlikely that the gene sequences seen in our study were from microbial contamination, ${ }^{47}$ because we did not detect Chlamydia and Mycoplasma contamination after four weeks of culture of calcifying nanoparticles. In addition, the homology of the 16S rRNA gene was so high that even only a few wrong bases may lead to failure of the sequence and a false group. Due to the small size of CNPs, decalcification and PCR may destroy their genetic material. Only part of the 16SrRNA gene sequences compared to the GenBank may lead to wrong classification.

In our study, we did not isolate calcifying nanoparticles in all placental calcification samples, suggesting that the amounts in these samples was too small to isolate or they may have been lost in some steps. We could also say that calcification depends on the amount of calcifying nanoparticles present.

Placental integrity is critical for proper embryonic development, and placental calcification may lead to diseases such as hypospadias and rickets. ${ }^{3,4}$ The mechanism for calcification remains undefined. Although the nanobacterialike particles which contain genetic-like materials were detected in placental calcification of early pregnancy, isolating and culturing nanoscale micro-organisms from placental calcification tissues have not been reported. ${ }^{48}$ In this work, we isolated nanobacteria from placental calcification tissues, grew them in cell culture conditions, and identified calcifying nanoparticles as nanobacteria by sequencing the 16S rRNA gene. Our study may help to establish the relationship between placental calcification and calcifying nanoparticles.

In the clinic, neonatal infections usually cannot be related to a specific pathogenic bacterium on microbiological 
cultivation. However, cultivation of calcifying nanoparticles required RPMI 1640 or Dulbecco's Modified Eagle's Medium with fetal bovine serum, which is not required for pathogenic bacteria. This suggests a possible way to detect infectious agents in cases of placental calcification or other infectious diseases of unknown etiology. Some studies have shown that antinanobacterial therapy is helpful for many nanobacteria-related diseases. ${ }^{49-52}$ These medicines may be used to treat placental calcification, hypospadias, and rickets in the future. In our study, ultrasonic diagnosis of placental calcification was confirmed by the presence of placental calcification in the placental tissues obtained by cesarean section. Thus, despite variability in other factors related to pregnancy, tissues with calcification degrees 1-3 were included in our study. Our study suggests that routine detection of calcifying nanoparticles may lead to new diagnostic and therapeutic methods in the management of diseases associated with placental calcification. Calcifying nanoparticles may even be used as a material for filling teeth and bone because of their hydroxyapatite components.

Calcifying nanoparticles could either result from or cause placental calcification. Studies have shown that the vitamin $\mathrm{D}$ receptor is not required for fetal mineral homeostasis or regulation of placental calcium transfer in mice, ${ }^{53}$ so further studies are necessary to determine how calcifying nanoparticles induce or exacerbate calcification and to clarify the relationship between pregnant women with placental calcification and stone formation. Understanding of calcifying nanoparticles in placental calcification may lead to new strategies in the prevention, diagnosis, and treatment of this condition in pregnant women, infants, children, and even adults.

\section{Acknowledgment}

This study was supported by the National Natural Science Foundation for Young Scholars of China (31000075). We express our gratitude to the Obstetrics Department at the First Affiliated Hospital of Chongqing Medical University for help in obtaining the placental calcification samples.

\section{Disclosure}

The authors report no conflicts of interest in this work.

\section{References}

1. Spirt BA, Cohen WN, Weinstein HM. The incidence of placental calcification in normal pregnancies. Radiology. 1982;142:707-711.

2. Chen KH, Chen LR, Lee YH. Exploring the relationship between preterm placental calcification and adverse maternal and fetal outcome. Ultrasound Obstet Gynecol. 2011;37:328-334.
3. Sabbagh Y, Carpenter TO, Demay MB. Hypophosphatemia leads to rickets by impairing caspase-mediated apoptosis of hypertrophic chondrocytes. Proc Natl Acad Sci U S A. 2005;102:9631-9642.

4. Fujimoto T, Suwa T, Kabe K, Adachi T, Nakabayashi M, Amamiya T. Placental insufficiency in early gestation is associated with hypospadias. J Pediatr Surg. 2008;43:358-361.

5. Szymanowski K, Chmaj-Wierzchowska K, Florek E, Opala T. Do calcification of placenta reveal only maternal cigarette smoking? Przegl Lek. 2007;64:879-881. Polish.

6. Burdan F, Szumilo J, Korobowicz-Markiewicz A, Dyndor K, Szumilo M, Klepacz R. Unusual interleukin-1 and-6 expression in fetal cartilage is associated with placental abnormalities. Folia Histochem Cytobiol. 2010;48:30-36.

7. Jones DM, Tobin BM. Isolation of mycoplasms and other organisms from the placenta after caesarean section. J Med Microbiol. 1969;2: $347-352$.

8. Kajander EO, Ciftcioglu N. Nanobacteria: An alternative mechanism for mechanism for pathogenic intra- and extracellular calcification and stone formation. Proc Natl Acad Sci U S A. 1998;95:8274-8279.

9. Kajander EO, Ciftcioglu N, Miller-Hjelle MA, Hjelle JT. Nanobacteria: controversial pathogens in nephrolithiasis and polycystic kidney disease. Curr Opin Nephrol Hypertens. 2001;10:445-452.

10. McKay DS, Gibson EK Jr, Thomas-Keprta KL, et al. Search for past life on Mars: Possible relic biogenic activity in Martian meteorite: ALH84001. Science. 1996;273:924-930.

11. Folk RL. SEM imaging of bacteria and nanobacteria in carbonate sediments and rocks. J Sediment Petrol. 1993;63:990-999.

12. Folk RL, Lynch FL. The possible role of nanobacteria (dwarf bacteria) in clay-mineral diagenesis and the importance of careful sample preparation in high-magnification SEM study. J Sediment Res A Sediment Petrol Process. 1997;67:583-589.

13. Sears DW, Kral TA. Martian "microfossils" in lunar meteorites? Meteorit Planet Sci. 1998;33(4):791-794.

14. Kim TH, Kim HR, Myung SC. Detection of nanobacteria in patients with chronic prostatitis and vaginitis by reverse transcriptase polymerase chain reaction. Korean J Urol. 2011;52(3):194-199.

15. Shen X, Ming A, Li X, Zhou Z, Song B. Nanobacteria: a possible etiology for type III prostatitis. J Urol. 2010;184:364-369.

16. Kumon H, Matsumoto A, Uehara S, et al. Detection and isolation of nanobacteria-like particles from urinary stones: long-withheld data. Int J Urol. 2011;18:458-465.

17. Ciftcioglu N, Haddad RS, Goldon DC. A potential cause for kidney stone formation during space flights: Enhanced growth of nanobacteria in microgravity. Kidney Int. 2005;67:483-491.

18. Wood HM, Shoskes DA. The role of nanobacteria in urologic disease. World J Urol. 2006;32:1-4.

19. Sedivy R, Battistutti WB. Nanobacteria promote crystallization of psammoma bodies in ovarian cancer. APMIS. 2003;111:951-954.

20. Hudelist G, Singer CF, Kubista E. Presence of nanobacteria in psammoma bodies of ovarian cancer: evidence for pathogenetic role in intratumoral biomineralization. Histopathology. 2004;45:633-637.

21. Zeng J, Yang F, Zhang W, Gong Q, Du Y, Ling J. Association between dental pulp stones and calcifying nanoparticles. Int J Nanomedicine. 2011;6:109-118.

22. Puskás LG, Tiszlavicz L, Rázga Z, Torday LL, Krenács T, Papp JG. Detection of nanobacteria-like particles in human atherosclerotic plaques. Acta Biol Hung. 2005;56:233-245.

23. Hu YR, Zhao Y, Sun YW, et al. Detection of nanobacteria-like material from calcified cardiac valves with rheumatic heart disease. Cardiovasc Pathol. 2010;19:286-292.

24. Zhang SM, Tian F, Jiang XQ, et al. Evidence for calcifying nanoparticles in gingival crevicular fluid and dental calculus in periodontitis. J Periodontol. 2009;80:1462-1470.

25. Jing J, Lu J, Hao Y, Han Y. Nanobacteria's potential involvement in enamel repair in caries. Med Hypotheses. 2009;73:359-360.

26. Jelic TM, Roque R, Yasar U, et al. Calcifying nanoparticles associated encrusted urinary bladder cystitis. Int J Nanomedicine. 2008;3: 385-390. 
27. Shiekh FA, Charlesworth JE, Kim SH, et al. Proteomic evaluation of biological nanoparticles isolated from human kidney stones and calcified arteries. Acta Biomater. 2010;6(10):4065-4072.

28. Jones JA, Ciftcioglu N, Schmid JF, Barr YR, Griffith D. Calcifying nanoparticles (nanobacteria): an additional potential factor for urolithiasis in space flight crews. Urology. 2009;73:210. e11-e13.

29. Zhou Z, Hong L, Shen X, et al. Detection of nanobacteria infection in type III prostatitis. Urology. 2008;71:1091-1095.

30. Ciftçioğlu N, Vejdani K, Lee O, et al. Association between Randall's plaque and calcifying nanoparticles. Int J Nanomedicine. 2008;3: 105-115.

31. Wang XJ, Liu W, Yang ZL, Wei H, Wen Y, Li YG. The detection of nanobacteria infection in serum of healthy Chinese people. Zhonghua Liu Xing Bing Xue Za Zhi. 2004;25:492-494. Chinese.

32. Agababov RM, Abashina TN, Suzina NE, Vainshtein MB, Schwartsburd PM. Link between the early calcium deposition in placenta and its nanobacterial-like infection. J Biosci. 2007;32:1163-1168.

33. Pasquinelli G, Papadopulos F, Nigro M. Nanobacteria and psammoma bodies: ultrastructural observations in a case of pathological placental calcification. Ultrastruct Pathol. 2010;34:344-350.

34. Giachelli CM, Speer MY, Li X, Rajachar RM, Yang H. Regulation of vascular calcification: roles of phosphate and osteopontin. Circ Res. 2005;96:717-722.

35. Young JD, Martel J, Young L, Wu CY, Young A, Young D. Putative nanobacteria represent physiological remnants and culture by-products of normal calcium homeostasis. PLoS One. 2009;4:1-35.

36. Young JD, Martel J. The rise and fall of nanobacteria. Sci Am. 2010;302: 52-59.

37. Urbano P, Urbano F. Nanobacteria: facts or fancies?. PLoS Pathogen. 2007;3:567-570.

38. Akirav $\mathrm{C}, \mathrm{Lu} \mathrm{Y}, \mathrm{Mu}$ J, et al. Ultrasonic detection and developmental changes in calcification of the placenta during normal pregnancy in mice. Placenta. 2005;26:129-137.

39. Abbott A. Battle lines drawn between 'nanobacteria' researchers. Nature. 1999;401:105.

40. Demir T. Is there any relation of nanobacteria with periodontal diseases? Med Hypotheses. 2008;70:36-39.

41. Zhang QH, Lu GS, Shen XC, et al. Nanobacteria may be linked to testicular microlithiasis in infertility. J Androl. 2010;31:121-125.
42. Hjelle JT, Miller-Hjelle MA, Poxton IR, et al. Endotoxin and nanobacteria in polycystic kidney disease. Kidney Int. 2000;57:2360-2374.

43. Drancourt M, Jacomo V, Lépidi H, et al. Attempted isolation of Nanobacterium sp. microorganisms from upper urinary tract stones. J Clin Microbiol. 2003;41:368-372.

44. Tanner MA, Goebel BM, Dojka MA, Pace NR. Specific ribosomal DNA sequences from diverse environmental settings correlate with experimental contaminants. Appl Environ Microbiol. 1998;64: 3110-3113.

45. Drancourt M, Bollet C, Carlioz A, Martelin R, Gayral JP, Raoult D. Evaluation of $16 \mathrm{~S}$ ribosomal DNA sequence analysis of a large collection of environmental and clinical unidentifiable bacterial isolates. J Clin Microbiol. 2000;38:3623-3630.

46. Cisar JO, Xu DQ, Thompson J, Swaim W, Hu L, Kopecko DJ. An alternative interpretation of nanobacteria induced biomineralization. Proc Natl Acad Sci US A. 2000;97:11511-11515.

47. Ciftçioglu N, Björklund M, Kuorikoski K, Bergström K, Kajander EO. Nanobacteria: an infectious cause for kidney stone formation. Kidney Int. 1999;56:1893-1898.

48. Guller S, Lachappelle L. The role of placental Fas ligand in maintaining immune privilege at maternal-fetal interfaces. Semin Reprod Endocrinol. $1999 ; 17: 39-44$

49. Candemir B, Ertas FS, Kaya CT, et al. Association between antibodies against calcifying nanoparticles and mitral annular calcification. J Heart Valve Dis. 2010;19:745-752.

50. Zhang QH, Shen XC, Zhou ZS, Chen ZW, Lu GS, Song B. Decreased nanobacteria levels and symptoms of nanobacteria-associated interstitial cystitis/painful bladder syndrome after tetracycline treatment. Int Urogynecol J. 2010;21:103-109.

51. Eby GA. A hypothesis for anti-nanobacteria effects of gallium with observations from treating kidney disease. Med Hypotheses. 2008;71: 584-590.

52. Singh SK, Agarwal MM, Sharma S. Medical therapy for calculus disease. BJU Int. 2011;107:356-368.

53. Kovacs CS, Woodland ML, Fudge NJ, Friel JK. The vitamin D receptor is not required for fetal mineral homeostasis or for the regulation of placental calcium transfer in mice. Am J Physiol Endocrinol Metab. 2005;289:133-144.
International Journal of Nanomedicine

\section{Publish your work in this journal}

The International Journal of Nanomedicine is an international, peerreviewed journal focusing on the application of nanotechnology in diagnostics, therapeutics, and drug delivery systems throughout the biomedical field. This journal is indexed on PubMed Central, MedLine, CAS, SciSearch $\AA$, Current Contents ${ }^{\circledR} /$ Clinical Medicine,

\section{Dovepress}

Journal Citation Reports/Science Edition, EMBase, Scopus and the Elsevier Bibliographic databases. The manuscript management system is completely online and includes a very quick and fair peer-review system, which is all easy to use. Visit http://www.dovepress.com/ testimonials.php to read real quotes from published authors. 